\title{
A crítica de Habermas ao paradigma "produtivista" como orientação emancipatória da esquerda
}

\author{
Rúrion Soares Melo
}

\section{RESUMO:}

COM BASE NA TESE DE QUE DEVEMOS ENTENDER A "DEMOCRACIA RADICAL" COMO O NÚCLEO NORMATIVO DE SOCIEDADES EMANCIPADAS, O ARTIGO EXPÕE A CRÍTICA DE HABERMAS AO PARAdIGMA "PRODUtIVISTA" COMO ORIENTAÇÃO EMANCIPATÓRIA DA ESQUERDA.

PALAVRAS-CHAVE: Habermas, EMANCIPAÇÃO, PARADIGMA PRODUTIVISTA, ESQUERDA

\section{ABSTRACT:}

STABLISHING THAT ONE SHOULD UNDERSTAND THE "RADICAL DEMOCRACY" AS THE NORMATIVE CORE OF EMANCIPATED SOCIETIES, the PAPER PRESENTS tHe CRITIQUe of Habermas against the "PRODUCTIVISTIC" PARADIGM AS EMANCIPATORY ORIENTATION OF THE LEFT.

KEY-WORDS: HABERMAS, EMANCIPATION, PRODUCTIVISTIC PARADIGM, LEFT

No seu artigo "Revolução recuperadora e a necessidade de revisão da esquerda", escrito por ocasião dos acontecimentos e das transformações ocorridas no leste europeu no final da década de 80, Habermas escreveu o seguinte:

A esquerda não-comunista não tem motivo algum para a depressão. Pode ser que alguns intelectuais da RDA tenham primeiramente de se adaptar a uma situação em que a esquerda da Europa ocidental se encontra há décadas - ter de transformar as idéias socialistas em autocrítica radicalmente reformista de uma sociedade capitalista que, juntamente com suas fraquezas, desenvolveu suas forças nas formas de uma democracia de massas do Estado social e democrático de direito. Depois da falência do socialismo de Estado, essa crítica é o único buraco de agulha através do qual tudo tem de passar. ${ }^{1}$

\footnotetext{
Doutorando pelo Departamento de Filosofia da USP e pesquisador do Núcleo Direito e Democracia do CEBRAP.

${ }^{1}$ Habermas, J. "Die nachholende Revolution und linker Revisionsbedarf". In: Die nachholende Revolution. Frankfurt/M: Suhrkamp, 1990, p. 203 (Habermas, J "Que significa socialismo hoje? Revolução recuperadora e necessidade de revisão de esquerda". In: Novos Estudos CEBRAP, 30, julho de 1991, p. 60).
} 
Esta passagem reflete uma questão que já ocupava grande parte dos trabalhos de Habermas, a saber, procurar definir uma perspectiva a partir da qual as condições de emancipação, quando presentes numa dada sociedade, fossem consideradas e analisadas de modo crítico. Em outras palavras, Habermas levanta novamente o problema de como a esquerda poderia definir suas inspirações teóricas e suas intuições normativas partindo de um diagnóstico sobre o Estado democrático de direito vinculado ao Ocidente capitalista.

Habermas não acreditava que o "socialismo real" continha as fontes normativas de um projeto político capaz de levar a condições emancipadas de uma vida justa e igualitária - assim como se mostrou ineficaz na utilização dos meios adequados para realizá-las. Mas a transformação dos regimes comunistas em democracias (ainda que fossem democracias "capitalistas") ainda permitiria afirmar que o sentido da emancipação não naufragou junto com a experiência concreta de um socialismo de Estado? Segundo a posição habermasiana, seria necessário que nos comportássemos de modo crítico em face das duas possíveis alternativas que se colocavam diante de nós. Diversos de seus estudos mostravam que a alternativa de um Estado democrático de capitalismo tardio não deixava de se apresentar como uma solução não problemática. Mas, além disso, as preocupações emancipatórias de forma alguma estavam no horizonte daqueles que se encontravam do lado oposto, atrelados à tradição liberal das sociedades capitalistas - tradição esta que hoje vê a si mesma como vencedora. Seus interesses, de ordem predominantemente econômica, já deram suficientes testemunhos de que se trata exatamente do contrário.

A situação desenhada parece grave. Novos e diferenciados problemas (crescente desigualdade entre países "ricos" e "pobres", as conseqüências negativas do crescimento econômico em relação a questões de meio-ambiente, as ondas migratórias, guerras nacionais, étnicas e religiosas, etc) são alguns dos desafios que as sociedades contemporâneas precisam enfrentar. E quando vislumbramos nossas alternativas considerando esse pano-de-fundo, temos a impressão de que as atuais sociedades democráticas correm o risco de que a política perca sua autocompreensão e orientação ligadas à autodeterminação e à 
autonomia. As dúvidas levantadas mesmo por aqueles que se encontram em democracias já estabelecidas deixam ver que "as instituições existentes da liberdade não são mais inatacáveis"2, causando uma "inquietação" cujo motivo, diz Habermas, é o de que "não se pode ter nem manter um Estado de direito sem democracia radical". ${ }^{3}$ Essa "inquietação" exige saber se uma "democracia radical" é possível nas condições atuais de uma sociedade capitalista.

Porém, os debates no século XX em torno dos ideais socialistas foram articulados, sobretudo, pela questão da revolução ou reforma do capitalismo - seja no debate político ou acadêmico. Muitos autores reconhecem que a dicotomia entre comunismo e social-democracia, que dominou os termos do debate sobre a esquerda no século $\mathrm{XX}$, estava situada nesse campo. ${ }^{4}$ Em linhas gerais, os comunistas acusam os socialdemocratas de trair os interesses da classe trabalhadora ao abandonarem os "fins últimos" da revolução do sistema capitalista. Os social-democratas procuram justificar caminhos alternativos para se imaginar uma sociedade na qual se possa combinar a intervenção do Estado com o mercado, com a finalidade de alcançar uma redistribuição mais planejada de recursos e prover assim mais oportunidades para a vida. Contudo, apesar dessa dicotomia, ambos preocupam-se prioritariamente com os melhores meios de se alcançar uma distribuição socialmente mais justa e igualitária que seja administrada pelo Estado. Em outras palavras, a maior parte do debate entre comunistas e social-democratas limitou-se ao sistema social e econômico - as condições que formariam uma sociedade emancipada implicavam em saber qual ordenamento econômico beneficiaria o maior número de pessoas nas sociedades. ${ }^{5}$

Por diversos motivos, a dicotomia dominante entre comunistas e social-democratas desapareceu. Já há muito tempo o comunismo falha-

${ }^{2}$ Cf. Habermas, J. Faktizität und Geltung. Frankfurt/M: Suhrkamp, 1998, p. 13 (Habermas, J. Direito e democracia. Rio de Janeiro: Tempo Brasileiro, 1997, Vol. 1, p. 13).

${ }^{3}$ Idem, Ibidem.

${ }^{4}$ Cf. Lemke, C.; Marks, G. (ed.) The crisis of socialism in Europe. Durham, 1992

${ }^{5}$ Essa abordagem centrada na questão da revolução ou reforma do sistema capitalista é predominante em historiadores, tais como Sasson, D. One hundred years of socialism. New York: The New Press, 1996; Eley, G. Forging democracy: The history of the left in Europe, 1850-2000. Oxford: Oxford University Press, 2002. E mesmo em Rosemberg, A. Democracia e socialismo. São Paulo: Global. 1999. 
va em criar um sistema social e econômico viável, assim como falhou também em desenvolver procedimentos democráticos que permitissem a legitimidade do regime frente à população, concentrando esforços no aparelhamento burocrático do Estado e do Partido. ${ }^{6}$ Por outro lado, os princípios social-democratas da igualdade, bem-estar e de intervenção do Estado no mercado, que durante muitos anos possibilitaram, apesar de seus inúmeros problemas, uma melhoria de vida para a maioria das pessoas, vêem sua manutenção ser cada vez mais solapada pelos imperativos da abertura do mercado que atingem ao menos três importantes pilares de seu programa: o estatismo ${ }^{7}$, a economia keynesiana e a manutenção do bem-estar social. ${ }^{8}$ Não demorou muito para que muitos anunciassem que "le socialisme est mort". ${ }^{9}$

Ora, apesar de forças e tendências objetivas contra partidos políticos, estratégias e concepções atrelados aos socialistas, as reflexões de Habermas permitem indagar se a então anunciada falência ou fracasso dos ideais da esquerda, ou mesmo o desencantamento do socialismo de um modo geral, não foi também resultado das limitações de um certo projeto e discursos que se mantiveram predominantemente voltados a uma preocupação em especial. A predominância do tema da transformação ou reforma do capitalismo na determinação dos termos do debate entre comunistas e social-democratas fez com que uma reflexão mais aprofundada sobre a "democracia" e as condições institucionais da realização da liberdade consistisse num problema derivado. Segundo comentários de Ruy Fausto, "o objeto que a crítica socialista atacava era (...) o capitalismo democrático. Porém, desde o início apareceu uma ambigüidade. A crítica do capitalismo (no início, a crítica da sociedade

${ }^{6}$ Cf. Reis Filho, D. A. As revoluções russas e o socialismo soviético. São Paulo: UNESP, 2003.

${ }^{7}$ Cf. Huhn, W. Der Etatismus der Sozialdemokratie. Freiburg: ça ira Verlag, 2003.

8 "Os social-democratas [...] perderam a fé na social democracia tradicional. Eles não estavam otimistas em relação ao seu próprio futuro. Eles tinham dúvidas sobre si mesmos [...] Seu 'realismo' era sinal de que eles resolveram aceitar o inevitável, a saber, a superioridade do capitalismo". Sasson, D. One hundred years of socialism, p. 733.

${ }^{9}$ Touraine, A. L'après socialisme. Paris: Grasset, 1983, p. 19. Sobretudo entre os "liberais", cf. Bobbio, N. L'utopia capovolta. Torino: La Stampa, 1990, e Dahrendorf, R. Após 1989: Moral, revolução e sociedade civil. São Paulo: Paz e Terra, 1997. Há ainda a polêmica interpretação de Fukuyama, F. The end of history and last man. Penguim: London, 1992. 
burguesa) era, às vezes, ao mesmo tempo, crítica da democracia”. ${ }^{10}$ Seria possível dizer, portanto, que um certo "desencantamento do socialismo" se deveu, em grande parte, motivado por um déficit democrático na herança teórica da esquerda que, aos olhos de Habermas, correspondia à insistência em se manter na pauta um paradigma "produtivista" como modelo de formas de vida emancipadas. Vamos desenvolver um pouco mais esse último ponto.

Em linhas gerais, a sociedade burguesa estruturou-se com tanta força através do trabalho abstrato, trabalho remunerado, regido pelo mercado, que se criou uma utopia que penetrou a esfera da produção, criando a imagem de uma sociedade emancipada como sociedade do trabalho. Mesmo a utopia dos primeiros socialistas condensava-se na imagem de uma organização social fundada no trabalho livre e igual dos produtores. Na Ideologia alemã, por exemplo, a identificação deste "paradigma produtivista" remetia a aspectos presentes numa concepção de emancipação que solucionasse o problema do trabalho heterônomo: nessa linha de interpretação, a autonomia, ou auto-atividade dos indivíduos ou das classes, só poderia ser alcançada quando os trabaIhadores se apropriassem coletivamente da totalidade da produção, identificando assim emancipação e desenvolvimento das forças produtivas. ${ }^{11}$ Ora, essa utopia de uma sociedade do trabalho deixou marcas fundamentais no projeto de um Estado social.

Quando faz seu diagnóstico das contradições e crises do Estado social, Habermas não se limita apenas à análise de problemas estruturais do capitalismo tardio. Em sua planificação global por meio da intervenção no processo de acumulação do capital, o Estado social não somente regulou o ciclo econômico em seu conjunto, criando e melhorando as condições para a utilização do excedente de capital acumulado, mas também substituiu o mecanismo de mercado por um novo compromisso político e social. Uma vez que a organização do capitalismo se transformou, a relação no capitalismo concorrencial entre trabalho assa-

\footnotetext{
${ }^{10}$ Fausto, R. "Totalitarismo". In: . A esquerda difícil. São Paulo: Perspectiva, 2007, p. 16-7.

${ }^{11}$ Cf. Marx, K.; Engels, F. "Die Deutsche Ideologie". In: Marx-Engels Werke. Band 3. Berlim: Dietz Verlag, 1990, p. 72.
} 
lariado e capital, bem como da esfera econômica frente à esfera política, que era considerada em grande medida "apolítica", pois reproduzia uma ideologia apoiada simplesmente nas relações de mercado, foi substituída por uma distribuição mais política do produto social, no qual o Estado, ou melhor, o aparelho estatal, assume funções de complementação e substituição do mercado, bem como planeja e administra os acordos entre os diferentes grupos de interesse em disputa.

Da perspectiva daqueles que apostaram no projeto do Estado social, seu "fim" consistia no aprofundamento de formas de vida igualitariamente estruturadas e na compensação das condições sociais desiguais da sociedade capitalista por meio da redistribuição mais justa de bens coletivos. Isso foi possível porque, ao intervir no processo de acumulação do capital, o Estado ampliou consideravelmente a produtividade do trabalho exatamente mediante a produção desses bens coletivos. ${ }^{12} \mathrm{E}$ nessa tentativa de remediar as falhas funcionais do mercado, o Estado também deveria dirimir os riscos básicos dos custos sociais da produção privada, sobretudo os riscos ligados ao trabalho assalariado, e garantir liberdade e justiça social à massa da população.

Esse programa do Estado social e democrático de direito, próprio do Ocidente capitalista, exigiu que a esquerda redefinisse seus ideais para que não perdessem a força orientadora da ação. Essa redefinição, aos olhos de Habermas, representou um avanço no seguinte sentido. Ela marcou o abandono, por parte da posição reformista social-democrata $^{13}$, da perspectiva dogmática da luta de classes (pois passava a instituir compromissos políticos e sociais entre empregadores e empregados); da falsa atitude frente ao Estado democrático de direito (não mais considerando o "direito" como mera super-estrutura, mas colocando-o no interior da pauta de negociação e de conquistas de direitos, como,

\footnotetext{
12 Habermas se refere nesse ponto tanto a fenômenos como créditos governamentais, subvenções, empréstimos (ligados ao crescimento sustentável, estabilidade da moeda e pleno emprego), melhoria de infra-estrutura material (transporte, saúde) e produtividade no trabalho (educação, programas de capacitação), até compensações sociais (seguro desemprego, bem-estar, equilíbrio ecológico, etc). Cf. Habermas, J. Legitimationsprobleme im Spätkapitalismus. Frankfurt/M: Suhrkamp, p. 79 e ss.

${ }^{13}$ Cf. Marramao, G. "Entre bolchevismo e social democracia alemã: Otto Bauer e a cultura política do austro-marxismo". In: Hobsbawm, E. (ed.). História do marxismo V. Rio de Janeiro: Paz e Terra, 1985.
} 
por exemplo, aqueles ligados à legislação trabalhista); da visão holista da sociedade e das hipóteses de fundo de uma ordem evolucionista. ${ }^{14}$ Para Habermas, o marxismo mantinha-se preso a estes discursos e enfraquecia sua capacidade de compreensão da realidade. ${ }^{15}$ Porém, ainda que representasse um avanço em termos de compreensão da realidade, os reformistas permaneciam presos à utopia marxista dominante de uma sociedade do trabalho.

Nesse sentido, o programa do Estado social manteve, nas palavras de Habermas, "o núcleo utópico" no qual as condições de vida emancipada e digna do homem correspondem às condições de trabaIho autônomo. ${ }^{16}$ Porém, as condições da emancipação não resultariam diretamente de uma transformação nas condições de trabalho, isto é, "de uma transformação do trabalho heterônomo em auto-atividade". ${ }^{17}$ Estas condições se apresentam sob outra forma no projeto do Estado social, devendo ser alcançadas por meio de reformas político-administrativas que visam a normalização do status do trabalho dependente, a participação política e os direitos sociais que devem propiciar à massa da população a chance de viver em segurança, justiça social e bemestar crescente. ${ }^{18}$

A partir da década de 60, os diagnósticos do Estado de bemestar social feitos por autores como Claus Offe ${ }^{19}$ e Habermas colocam

\footnotetext{
${ }^{14}$ Cf. Habermas, J. "Die nachholende Revolution und linker Revisionsbedarf". In: Die nachholende Revolution, p. 189-91. (p. 50-2). Para uma discussão mais ampla cf. Tomberg, F. Habermas und der Marxismus. Würzburg: Königshausen \& Neumann, 2003. ${ }^{15}$ Anthony Giddens, resumindo em parte este aspecto da discussão em torno do Estado de bem-estar social, diz que "o marxismo ortodoxo não pode iluminar alguns dos fenômenos-chave do capitalismo tardio, no qual a intervenção estatal é cada vez mais extensa e na qual se mantém a democracia de massas e as reformas para o bem-estar social". Giddens, A. "Razón sin revolución? La Theorie des kommunikativen Handels de Habermas”. In: Bernstein, R. (ed). Habermas y la modernidad. Madrid: Cátedra, 1999, p. 175.

${ }^{16}$ Cf. Habermas, J. "Die Krise des Wohlfahrtsstaates und die Erschöpfung utopischer Energien”. In:_. Die neue Unübersichtlichkeit. Frankfurt/M: Suhrkamp, 1985, p. 147 (Habermas, J. "A nova intransparência: A crise do Estado de bem-estar social e o esgotamento das energias utópicas". In: Novos Estudos CEBRAP, 18, setembro de 1987, p. 107). 17 Idem, Ibidem.

${ }^{18}$ Cf. Habermas, J. "Volkssouveränität als Verfahren". In: Faktizität und Geltung,

p. 618. (Cf. Habermas, J. "A soberania do povo como processo". In: . Direito e democracia, vol. 2, p. 266).

${ }^{19} \mathrm{Cf}$. Offe, C. Problemas estruturais do Estado capitalista. Rio de Janeiro: Tempo Brasi-
} 
em questão o preço dessas reformas e, sobretudo, o objetivo das políticas compensatórias e os "meios" de sua realização: se por um lado estas políticas procuram humanizar e contrabalançar os riscos básicos do trabalho assalariado, por outro lado não conseguem fugir da meta do pleno emprego, garantindo ao cidadão somente a indenização enquanto cliente da burocracia com pretensões de direito e seu papel de consumidor de bens de massa com poder de compra. Em relação ao processo político, o reformismo que segue o caminho das intervenções estatais faz com que a formação política da vontade se desloque para um sistema político em expansão que se programa a si mesmo, adquirindo autonomia em relação às fontes democráticas de sua legitimação - limitando o processo de legitimação à auto-regulação administrativa. E essa expansão da racionalidade administrativa pode gerar uma crise de legitimação, uma vez que, sem uma formação discursiva da opinião e da vontade que tematize publicamente conteúdos e normas imprescindíveis à reprodução social, não é possível criar ou manter estruturas normativas legitimadoras meramente com meios administrativos. ${ }^{20}$

Ao mesmo tempo, a social-democracia cada vez menos pode manter a idéia de um processo que passa do mercado à democracia: tem que pagar um preço alto aprendendo "a viver com as conseqüências normativas indesejáveis do crescimento capitalista - e também com os riscos do mercado de trabalho, riscos que, específicos do sistema, podem ser social e politicamente 'amortecidos', mas não afastados". ${ }^{21}$ Os sindicatos e partidos reformistas que operaram num quadro de Estado democrático de direito se frustraram ao tentar concretizar o compromisso do Estado de bem-estar social, ou melhor, tiveram que se contentar com uma simples adaptação da herança liberal-burguesa e renunciar ao cumprimento das promessas de uma "democracia radical".

leiro, 1984. Também Offe, C. Capitalismo desorganizado. São Paulo: Brasiliense, 1995, e Offe, C. Herausforderungen der Demokratie. Frankfurt/M: Suhrkamp, 2003. Para um panorama da discussão de Habermas e Offe, assim como a elaboração de uma crítica própria frente ao Estado social, cf. Keane, J. Public life and late capitalism: Toward a socialist theory of democracy. Cambridge University Press, 1984.

${ }^{20} \mathrm{Cf}$. Habermas, J. Legitimationsprobleme im Spätkapitalismus. Frankfurt/M: Suhrkamp, 1973, p. 70 e ss.

${ }^{21}$ Habermas, J. "Die nachholende Revolution und linker Revisionsbedarf". In:

Die nachholende Revolution, p. 192 (Habermas, J. "Que significa socialismo hoje? Revolução recuperadora e necessidade de revisão de esquerda". In: Novos Estudos CEBRAP, p. 53). 
Assim, uma contradição habita no interior do projeto do Estado social: os "fins" emancipatórios visando criar e manter formas de vida estruturadas igualitariamente, garantindo a liberdade de movimentos para a autonomia e individuação de sujeitos socializados, não podem ser diretamente alcançados pela transposição jurídico-administrativa de um programa político. Com isso, "não foi o Estado social que se revelou uma ilusão", diz Habermas, "mas a expectativa de poder realizar formas emancipadas de vida através de meios administrativos". ${ }^{22}$

É importante notar que se os "meios" intervencionistas utilizados para a realização dos programas do Estado social apontam para uma espécie de "sociedade totalmente administrada", o diagnóstico de Habermas (e, neste caso, também o de Claus Offe) sobre o capitalismo tardio difere em alguns pontos daquele formulado por Adorno. ${ }^{23}$ Habermas endossa o argumento de Adorno de acordo com o qual formas de vida burocratizadas e administradas continuam sendo um princípio organizador das sociedades de capitalismo tardio. Porém, esse princípio global de racionalização administrativa, na perspectiva de Habermas, envolve necessariamente "contradições" e "crises". O Estado social é incapaz de realizar estruturalmente as condições institucionais que assegurassem a lealdade das massas por meio da dominação burocrática. Contrário à posição não somente de Adorno, mas também à teoria de Marcuse sobre a sociedade tecnológica e pós-industrial24, Habermas constata que o capitalismo tardio não pode homogeneizar e unificar a vida social e política em direção a um totalitarismo racionalizado. ${ }^{25}$

\footnotetext{
22 Idem, Ibidem (Idem, Ibidem).

${ }^{23}$ Cf. de Adorno, T. W.; Horkheimer, M. Dialektik der Aufklãrung. In: Gesammelte Schriften 3. Frankfurt/M: Suhrkamp, 1997 (Adorno, T. W.; Horkheimer, M. Dialética do esclarecimento. Rio de Janeiro: Jorge Zahar, 1985). Marcos Nobre faz uma discussão aprofundada do diagnóstico do capitalismo tardio proposto por Adorno, confrontando-o com Habermas. Cf. Nobre, M. A Dialética Negativa de Theodor W. Adorno: A ontologia do estado falso. São Paulo: Iluminuras, 1998, principalmente cap. 1. Para uma comparação entre Adorno, Habermas e Offe, cf. ainda Keane, J. Public life and late capitalism: Toward a socialist theory of democracy, principalmente cap. 3.

${ }^{24}$ Cf. Marcuse, H. One-dimensional man: Studies in the ideology of advanced industrial society. London: Routledge, 1991.

${ }^{25}$ Procurando ilustrar um ponto significativo nas divergências entre Adorno e Habermas, Marcos Nobre lembra que "estas diferenças entre os dois autores revela, mais uma vez, as diferentes posições que assumem frente aos escritos de Pollock. Enquanto
} 
Os limites de um programa que visa à administração total da sociedade sobre si mesma têm sido tratados há muito tempo por Habermas em vários de seus livros. Um dos argumentos centrais consiste no fato de que o próprio diagnóstico das "contradições" e "crises" do capitalismo tardio encontra-se apoiado numa estruturação altamente diferenciada das sociedades complexas na qual a organização da sociedade sobre si mesma mediante a auto-determinação soberana do povo só pode se realizar paralelamente ao lado de um sistema econômico regulado pelo mercado e de um sistema administrativo regulado pelo poder. Em contrapartida, só podemos identificar a "caixa de ressonância" da crise do Estado social no modo como os sistemas do dinheiro e do poder se articulam com o compromisso entre Estado e sociedade, compromisso que "constitui o fundamento do qual qualquer política tem de partir em nossos domínios". ${ }^{26}$ As constantes intervenções estatais rompem com esse compromisso em função de sua autoridade planificadora, tornando mais claro que "as conseqüências secundárias da juridificação (Verrechtlichung) e da burocratização tiraram a inocência do meio aparentemente neutro do poder administrativo, com o qual a sociedade pretendia atuar sobre si mesma. Agora também o Estado intervencionista tem de ser 'socialmente controlado'”. ${ }^{27}$ Por essa razão, a ampliação radical de espaços democráticos requer, "sem dúvida", tornar o programa do Estado social, em seu todo, mais reflexivo - ou seja, forçando o Estado a considerar a autodeterminação política da sociedade.

Para Habermas, a bancarrota do "socialismo de Estado" e os novos movimentos sociais ocorridos no leste europeu, por exemplo, foram sintomáticos para se repensar não apenas os significados históricos, mas também os limites dos estímulos teóricos e orientações

\footnotetext{
Habermas parte da concretização do 'capitalismo de estado na sua forma democrática', Adorno vê no Welfare State um elemento pertubador do diagnóstico - consolidado na década de 40 - de que se seguia em direção à sociedade totalmente administrada (i. e., uma variante do 'capitalismo de estado em sua forma autoritária')". Nobre, M. $A$ Dialética Negativa de Theodor W. Adorno: A ontologia do estado falso, p. 47, em nota. ${ }^{26}$ Habermas, J. "Die nachholende Revolution und linker Revisionsbedarf". In: Die nachholende Revolution, p. 197 (Habermas, J. "Que significa socialismo hoje? Revolução recuperadora e necessidade de revisão de esquerda". In: Novos Estudos CEBRAP, p. 56). ${ }^{27}$ Idem, p. 199 (Idem, p. 57).
} 
normativas da esquerda. Certamente, a esquerda não-comunista - que não se culpou pela falência de um socialismo de Estado que ela sempre criticou - "não deve agir como se nada tivesse acontecido". ${ }^{28}$ As mudanças revolucionárias na União Soviética, Polônia, Hungria, etc., e principalmente no caso da anexação na Alemanha, foram seguidas por um caminho que visava "recuperar" desenvolvimentos perdidos: a vinculação político-social com as formas de relação e vida do capitalismo desenvolvido e com a tradição político-institucional das revoluções burguesas, vinculação que Habermas chamou de "revolução recuperadora", pois apontava para a consolidação de uma sociedade de bem-estar e de constituição democrática. E este retorno ao Estado democrático de direito deve poder ser acompanhado de uma transformação radicalmente democrática da relação entre Estado e sociedade, uma vez que foi fruto de movimentos e críticas ao Estado e, ao mesmo tempo, tornaria possível superar a alternativa clássica entre reforma ou revolução. ${ }^{29}$

Conseqüência já das crises características do capitalismo de Estado e dos efeitos colaterais de uma repolitização do quadro institucional por meio de maciça intervenção estatal, essa "revolução recuperadora" aponta para a ampliação de espaços democráticos por trás das linhas do planejamento administrativo do Estado social. Os novos movimentos sociais, respondendo às desastrosas conseqüências do "estatismo social" para diferentes formas de vida, formas de participação, solidariedade e autonomia, tornam o Estado social mais reflexivo ao constituírem demandas pela conquista de direitos e garantias individuais, passando por problemas de redistribuição econômica e compensações sociais, até reivindicações por reconhecimentos de identidades coletivas marginalizadas (estamos nos referindo a fenômenos diversos que abrangem, por exemplo, grupos em defesa do meio-ambiente, às discussões sobre direitos humanos, às pautas de minorias contra discriminação racial ou de gênero, como no caso de negros e mulheres, políticas afirmativas, etc). Estes fenômenos acirram a relação entre demo-

\footnotetext{
${ }^{28}$ Idem, p. 188 (Idem, p. 50).

${ }^{29}$ Cf. Cohen, J.; Arato, A. Civil society and political theory. Massashussets: MIT, 1995, sobretudo a Introdução.
} 
cracia radical e Estado de direito e lançam nova luz ao sentido que a esquerda deve atribuir hoje aos seus ideais emancipatórios.

Trata-se, portanto, de circunscrever as condições nas quais seria possível tornar o Estado social mais reflexivo e ampliar os espaços de autonomia sob as circunstâncias de uma democracia de massas. E essa é uma passagem central para compreender de que modo a utopia de uma sociedade do trabalho dá lugar à luta em torno da integridade e autonomia dos estilos de vida, espaços de auto-realização, conquistas de direitos e autodeterminação pública. Em outras palavras, os problemas de legitimidade e o conflito entre Estado e sociedade demarcam cada vez mais os limites do paradigma produtivista, de seus "meios" burocráticos e intervencionistas no processo de autodeterminação pública, ampliando os espaços para a radicalização democrática e para o sentido emancipatório reconstruído sob um novo paradigma. As esferas públicas autônomas teriam de alcançar uma combinação de poder e auto-limitação que poderiam tornar os mecanismos de auto-regulação do Estado e da economia suficientemente sensíveis diante dos resultados orientados com vistas a uma formação radicalmente democrática da vontade. Esta formação deve ser conforme ao espírito de uma democracia radical, na qual a esquerda socialista pode encontrar, por sua vez, "seu lugar e seu papel político".30

\section{BIBLIOGRAFIA}

ADORNO, T. W.; HORKHEIMER, M. Dialética do esclarecimento. Rio de Janeiro, Jorge Zahar, 1985. ; __ Dialektik der Aufklãrung. In: Gesammelte Schriften 3. Frankfurt/M: Suhrkamp, 1997.

BOBBIO, N. L'utopia capovolta. Torino: La Stampa, 1990.

COHEN, J.; ARATO, A. Civil society and political theory. Massashussets: MIT, 1995.

COUTINHO, C. N. Marxismo e política: a dualidade de poderes e outros ensaios. São Paulo: Cortez, 1996.

. "A dualidade de poderes: Estado e revolução no pensamento marxista".

\footnotetext{
${ }^{30}$ Habermas, J. "Die nachholende Revolution und linker Revisionsbedarf". In: Die nachholende Revolution, p. 202 ( Habermas, J. "Que significa socialismo hoje? Revolução recuperadora e necessidade de revisão de esquerda". In: Novos Estudos CEBRAP, p. 60).
} 
In: $\quad$ Marxismo e política: a dualidade de poderes e outros ensaios. São Paulo: Cortez, 1996.

" "Os marxistas e a 'questão democrática". In: Marxismo e política: a dualidade de poderes e outros ensaios. São Paulo: Cortez, 1996.

DAHRENDORF, R. Após 1989: Moral, revolução e sociedade civil. São Paulo: Paz e Terra, 1997.

ELEY, G. Forging democracy: The history of the left in Europe, 1850-2000. Oxford: Oxford University Press, 2002

FAUSTO, R. "Totalitarismo". In:___ A esquerda difícil. São Paulo: Perspectiva, 2007.

FUKUYAMA, F. The end of history and last man. London: Penguim, 1992.

GIDDENS, A. "Razón sin revolución? La Theorie des kommunikativen Handels de Habermas". In: BERNSTEIN, R. (ed). Habermas y la modernidad. Madrid: Catedra, 1999.

HABERMAS, J. Legitimationsprobleme im Spätkapitalismus. Frankfurt/M: Suhrkamp, 1973.

A crise de legitimação no capitalismo tardio. Rio de Janeiro: Tempo Brasileiro, 1980.

Theorie des kommunikativen Handelns. 2 Bde. Frankfurt/M: Suhrkamp, 1981. "Die Krise des Wohlfahrtsstaates und die Erschöpfung utopischer Energien". In: _. Die neue Unübersichtlichkeit. Frankfurt/M: Suhrkamp, 1985.

"A nova intransparência: A crise do Estado de bem-estar social e o esgotamento das energias utópicas". In: Novos Estudos CEBRAP, 18, setembro de 1987.

. "Die nachholende Revolution und linker Revisionsbedarf" In: Die nachholende Revolution. Frankfurt/M: Suhrkamp, 1990.

"Que significa socialismo hoje? Revolução recuperadora e necessidade de revisão de esquerda". In: Novos Estudos CEBRAP, 30, julho de 1991. Direito e Democracia: Entre Facticidade e Validade. 2 Vols. Rio de Janeiro: Tempo Brasileiro, 1997.

Faktizität und Geltung. Frankfurt/M: Suhrkamp, 1998.

- "A soberania do povo como processo". In: Direito e Democracia: Entre Facticidade e Validade. Vol.2. Rio de Janeiro: Tempo Brasileiro, 1997. "Volkssouveränität als Verfahren". In: Frankfurt/M: Suhrkamp, 1998

HUHN, W. Der Etatismus der Sozialdemokratie. Freiburg: ça ira Verlag, 2003.

KEANE, J. Public life and late capitalism: Toward a socialist theory of democracy. Cambridge University Press, 1984.

LEMKE, C.; MARKS, G. (ed.) The crisis of socialism in Europe. Durham, 1992.

MARCUSE, H. One-dimensional man: Studies in the ideology of advanced industrial society. London: Routledge, 1991.

MARRAMAO, G. "Entre bolchevismo e social democracia alemã: Otto Bauer e a cultura política do austro-marxismo". In: HOBSBAWM, E. (ed.). História do marxismo V. Rio de Janeiro: Paz e Terra, 1985.

MARX, K; ENGELS, F. "Die Deutsche Ideologie". In: Werke. Band 3. Berlim: Dietz Verlag, 1990. Marx-Engels

NOBRE, M. A Dialética Negativa de Theodor W. Adorno: A ontologia do Estado falso. São Paulo: lluminuras, 1998.

OFFE, C. Problemas estruturais do Estado capitalista. Rio de Janeiro: Tempo Brasileiro, 1984.

Capitalismo desorganizado. São Paulo: Brasiliense, 1995.

. Herausforderungen der Demokratie. Frankfurt/M: Suhrkamp, 2003. 
A CRÍTICA DE HABERMAS AO PARADIGMA...

RÚRION SOARES MELO

REIS FILHO, D. A. As revoluções russas e o socialismo soviético. São Paulo: UNESP, 2003.

ROSEMBERG, A. Democracia e socialismo. São Paulo: Global, 1999.

SASSON, D. One hundred years of socialism. New York: The New Press, 1996.

TOMBERG, F. Habermas und der Marxismus. Würzburg: Königshausen \& Neumann $\mathrm{GmbH}, 2003$.

TOURAINE, A. L'après socialisme. Paris: Grasset, 1983.

WELLMER, A. "Über Vernunft, Emanzipation und Utopie". In: Ethik und Dialog. Frankfurt/M: Suhrkamp, 1986.

"Razón, utopía y la dialéctica de la ilustración". In: BERNSTEIN, R. (ed). Habermas y la modernidad. Madrid: Catedra, 1999. 